\title{
The Linguistic Technique of Parallelism in Al-Ahwas Al-Ansari's Poetry: A Stylistic Study
}

\author{
Mah'd Ahmad Al-halhooli \\ Department of Arabic Language and Literature, The Hashemite University, P.O. Box 330127, Zarqa 13133, Jordan \\ E-mail: asad@hu.edu.jo \\ Nisreen Al-Khawaldeh (corresponding author) \\ Department of English Language and Literature, The Hashemite University, P.O. Box 330127, Zarqa 13133, Jordan \\ E-mail: nal-khawaldeh@hu.edu.jo \\ Halla Shureteh \\ Department of English Language and Literature, The Hashemite University, P.O. Box 330127, Zarqa 13133, Jordan \\ E-mail: halla@hu.edu.jo
}

Received: 22-07-2016

Published: 02-01-2017
Accepted: 19-09-2016

doi:10.7575/aiac.ijalel.v.6n.1p.189
Advance Access Published: November 2016

URL: http://dx.doi.org/10.7575/aiac.ijalel.v.6n.1p.189

\begin{abstract}
Parallelism is one of the most conspicuous stylistic techniques that are marked by the receiver's ear, and it also has an excellent musical rhythm. Al-Ahwas ${ }^{1}$ thoroughly familiarizes readers with an entire host of parallelistic arrangements in his poetry, which makes the semantic units a rich material for the aesthetic study. The present study presents the most beautiful uses of all varieties of parallelism in a corpus of Al-Ahwas's poetry, as the reader of his poetry would never miss observing the many images of parallelism based on semantic concordance, as well as the parallelism that appears in one line, or in a stanza, based on structural concordance, in addition to the parallelism formed by the morphological rhythm which is based on the repetition of a morphological derivative formulae. Al-Ahwas did not suffice himself with the similar morphological formulae to achieve rhythm, but he also aimed at the parallelism achieved by repetition, which falls into several patterns. They can be included in one verse line, or within a number lines conforming to one idea, but with different contexts. The second pattern of repetition in terms of rhythm and structure is Epanaphora, or Epanalepsis: which is a repetitive structure based on inserting a word at the beginning of the speech and then repeating the same word at the end of the speech. Al-Ahwas achieved a high rhythmical harmony using parallelism besides a semantic goal by deliberately intensifying parallel words and functioning units in a network revolving around the dominant idea. This study hopes to pave the way for future avenues of studies in poetry under the category of stylistics.
\end{abstract}

Keywords: Parallelism, stylistics, Al-Ahwas's poetry

\section{Introduction}

Parallelism is one of the most distinctive stylistic techniques that are marked by the receiver's ear, and it also has an excellent musical rhythm. The parallelism is a form of text cohesion and interdependence of its parts, and it is deemed an effective element in strengthening the text plot, linking the text at a high level of organization and balance, thus, it is a total image that rounds the text and surrounds it, but it is made up of multiple parts, for parallelism reveals unexpected renewable potentials in responsive hymns of music which is a distinctive rhythmic phenomenon.

The parallelism in critical studies (Muftah, 1999; Thamer, 1987; Rawashdeh, 1998, David, 2006) is a concept which is summarized by observing the linguistic structures that have equivalent relations based on the principle of the equitable linguistics in the compounding structure of synthetic-based duo authoring that creates a kind of linguistic parallel geometric distribution among the elements of the structure that shows samples of duplication and concordance (see AlWali, and Hanoon, 988). It combines between rhetorical morphology in compositions and the principle of parallelism because the work of these forms is closely related to the structural coherence and interference level. As Al-Qura'an (1999) argues that "This stems from the nature of parallelism that imposes itself on the textual structure of poetry as a structural feature of the texts that relies on rhetorical and aesthetic shapes as fundamental means in its constitute ".

The root of the verb (Wazi) shows that it has multiple meanings in Arabic dictionaries, but what concerns us among all these meanings is the meaning of interview and confrontation (Bin Zakaria, 1972; Al-Shirazi, (1896). It is mentioned in the philosophical dictionary: it is vividly shown that parallelism term has two meanings, a linguistic meaning and a

\footnotetext{
1. The poet Al-Ahwas Al-Ansari. He is Abdullah bin Mohammed bin Abdullah bin Asim bin Thabit al-Ansari, one of the Umayyad poets, died in Damascus in 105 AH / 723 AD. He was called Al-Ahwas for a tightness in his eye. He is an Islamic satire poet.
} 
terminological one. The linguistic meaning is defined as parallelism, but the terminological meaning of parallelism is a defined as a structural component in poetry based on the repetition of equal parts (Saliba, 1982; Matloob, (1986). The Arabic Rhetoric in Arab books talked about the movement of proportionality and equivalence based on parallelism and balance in poetry and prose in scattered places without pooling this disperse in one place, so, we find that Arabic rhetoric contains many terms: studding, kinds of similarity, and equivalence, even though we may find meanings of these terms overlapping sometimes (Knoni, 1999).

Here Thamer (1987) talked about techniques of parallelism as a characteristic feature of Arabic Poetry speech. Also, he pointed out that it is potential to benefit from the ancient rhetorical and critical effort in this area, "We can study a lot of parallelism formats to benefit consciously of inherited rhetorical data and Arab criticism at more than one level" he said. He also had made the rhetorical level one of these levels. At the rhetorical level, we can see a lot of aesthetic appearances and performance as simile, metaphor, and equality, Resemblance in shape, synonymy and so colon." he said. There is no doubt that these attempts to make the principle of parallelism controls, while many rhetorical structures lead us to try to test this technique and its effective ability in the Arabic poetic speech.

Parallelism was mentioned in many definitions in the critical modern efforts - for example - it was defined as: a symmetry exists between two parts of the linguistic chain itself, thus it was interpreted that these two part are genuinely two sentences having had the same structure itself, so that there will be a really strong relationship based either on the basis of similarity, or based on the basis of contrast (Thamer, 1987). It was also defined as: (two successive consecutives or more of the same morphological grammatical system accompanying with repetitions or rhythmic, acoustic or lexical ((semantic)) differences) (Thamer, 1987). It was also defined as: (context closeness and synonymy between two contents or two narratives in order to demonstrate that they are similar or different. The Emphasis is placed on the matches or contrast of the sides by rhythmic or synthetic repetitions) (Muftah, 1997).

It is noted that the principle of repetition is included in the principle of parallelism as part of the outreach process in the modern poetic speech based on the structural and organizational parallels. Roman Jacobson cites that J. M. Hopkins had observed this principle and believed that repetition of the grammatical image itself alongside the returning vocal image itself is the principle that constitutes the poetic impact, where he says: " The decorative side in poetry" but also we make no mistake when we say that every decoration is paraphrased as the principle of parallelism and the structure of poetry is a structure of a continuous parallelism (Khatib, 1982: 229).

\section{The Research problem}

The researchers were motivated to study the parallelism technique due to its importance. As Guillén (1987: 507) argues that it has an aesthetic pleasure as it "harmonizes the expression of the same thought in two sentences which either repeat the same idea in different words (synonymic), or counterpose two different thoughts (antithetic), or add to the thought by means of a variant expression which is not purely repetitive (synthetic)". Thus, it helps poets construct their poems into one unified understandable whole (Waugh 1980). This means that parallelism, as Short (1996) claims, has the power not just to foreground texts' parts of for readers, but also to make readers look for equivalents or contrastive connotations that link between those comparable parts. Al-Ahwas was specifically considered in the present study as he was one of the most brilliant and influential Umayyad poets. Al-Ahwas thoroughly familiarizes readers with an entire host of parallelistic arrangements in his poetry, which makes the semantic units a rich material for the aesthetic study.

Besides, though there are some studies conducted on parallelism employed in Arabic poetry (Sultan, 2011; Habil, 2014; Bouraoui, 2006; Agha, 2007), to the best of the researchers' knowledge, no study has been done on parallelism as a main stylistic device employed in Al-Ahwas's poetry.

\section{Aim of the study}

This study aims to address the aesthetics of parallelism within the structure of the poetic text of the Umayyad poet AlAhwas Al-Ansari, and provide a full account of parallelism by identifying and analysing the different existing linguistic patterns of parallelism. It also tries to test the ability of this technique to produce an aesthetic text on one hand, and demonstrates significance on the other hand. Thus, its importance stems from the fact that it sheds light on a distinctive linguistic phenomenon with creative importance. It pictures the poet artistic photos and produces his effective poetic music.

\section{Methodology}

This is a corpus-based study that analyses Umayyad poetry in particular Al-Ahwas's poetry. In order to achieve the study's aims, the language of the Al-Ahwas's poems was analyzed stylistically. The study follows the descriptive analytical approach, which extrapolates and analyzes the poetic texts to examine all the levels of parallelism. The analysis identified and clarified the different patterns of parallelism on different linguistic levels with examples. This is a stylistic study that sheds some light on the nature of the language of Arabic poetry. Short (1996) states that stylistics is concerned with connecting linguistic description to interpretation of denotation. This linguistic phenomenon makes a particular idea or structure obvious and more recognizable, thus it helps readers understand the suggested meaning, argue expressed points of view and convey the intended message. Thus, it is expected that the present study will add to literary studies as well as linguistic studies.

\section{Results and discussion}

\subsection{Examples of aesthetics of parallelism in Al-Ahwas's poetry}

This section present examples of aesthetics of parallelism in Al-Ahwas's poetry. Al-Ahwas established most of his texts on parallelism in multiple patterns, and this parallelism which he resorted to makes the semantic units written in these texts in parallel structures a rich material for artistic lesson. 
The one who looks at the texts of the poet would never miss the many images of parallelism based on semantic concordance, since this is considered one of the mainly important stylistic techniques that contribute to the semantic effectiveness, and stimulates the recipient through its musicality, resulting in comprehension, as well as textual cohesion at the levels of sound and structure.

Here the poet "Al-Ahwas' 'says:

And he said entrust all your secrets to us that we'd take care of

And I have no one to entrust them to. ${ }^{2}$

They want an implicit secret hidden in my heart

And some secrets are unobserved ${ }^{3}$

His repetition of the word "secret" in the first and second hemistiches came to emphasize the importance of the idea, trying to create overtones and new musical rhythms. This repetition has achieved a vocal harmony which contributes to the enrichment of the analytical energy for poetry. When the elements of this vocal harmony recur, wholly or partly, and have balanced rhythms and similar formal structures, it is called parallelism.

It could also be said that formalistic symmetry at the surface level between two words describing alienation in the following verse:

Don't think the stranger is the one who's left alone

But the one whom you leave is a stranger ${ }^{4}$

This amount of similarity of reacted contextual vocabularies has produced a profound structural symmetry. Such symmetry was intended to emphasize the verb in spite of the lexical difference of contextual vocabularies, which is demonstrated by the general or surface meaning, since poetry indicated one meaning which is "the poet $s^{\prime}$ mental alienation":

This verse shows that linking repeated words to context's vocabularies makes balance among the amount of vocabularies used to link the repeated word "alienation", because this huge amount of vocabularies is related with contextual ties covering the area of vocabularies in the poetic verse" (Al-Qura'an, 1996: 74).

There are many examples on this kind of repetition, such as this line of poetry:

You hope we go blind to scare parting

We hope we go blind and you scare it

I swear a parting scared me

That my heart broke ${ }^{5}$.

Or this one:

And he praised remembering the past days

As indebted who wants to pay his debt. ${ }^{6}$

Thus, the repeated word in the previous verses and in other examples, which are not mentioned to avoid prolongation, referred to the page where it is found in the poet's divan ${ }^{7}$, constituted a semantic core crowded with words to weave a garment of meanings that poet wanted to present around this core. Looking at these structures and what was repeated at the beginning or in the end of verses one can see that the repeated words in the text were the center of significance, and these repeated words were a signal for the poet's concerns that he repeatedly mentions when his sense requires feeling it (Al-Gharaibeh, 1999).

Parallelism also appears in the similarity based on structural symmetry in a verse or a poem. Parallelism can usually be seen in the similarity between two parallels as both important in terms of content and meaning and identical in terms of shape, sequence, and order as follows:

Her goodness Om Jaafar denied

Her goodness Om Jaafar I need.

My visit she denied after admitting

Grudges only brought that to me.

The following verses focus on one issue which is "visit" sharing the meaning and significance:

${ }^{2}$ Qtous, B. (1999). Rhythmic Structures in Mahmoud Darwish s' Group (Hesar Lmeda'ah Al-Baher), Journal of Yarmouk Research 9 , (1) 63-72.

${ }^{3}$ Ibid, p126.

${ }^{4}$ Al-Ahwas's poetry, (P. S),p126

${ }^{5}$ Al-Ahwas's poetry, (P. S), p 150.

${ }^{6}$ Ibid (P. S), p 206.

${ }^{7}$ Ibid (P. S), pp.144, 167, 206 \& 209 
Moving wishing to see Om Jaafar

In your house or I move not,

I visit the houses close to hers

And my heart longs to the house that I cannot visit,

A visitor I am not but passion moves me around

If not visited I have to visit,

I visit and I don't stop visiting whenever

I see an enemy pointing at me. ${ }^{8}$

Another example of this type of parallelism is evident in two poetic lines of Abi Tammam's poem on the conquest of Amuriyah". In these lines, it is noticeable that the repetition of the letter " $\mathrm{B}$ " which causes frequent sharp impact achieved through parallel voice proportionate to the subject of the poem and in line with rhyme gives internal as well as external music especially when stopping on the letter "B".

The morphological rhythm is the parallelism which is based on repeating a morphological derivative formula sequentially without having the same linguistic origin among the repeated formulas that connect them (Al-Assad, 1999); but each formula includes different linguistic root as the words of the poet in his poem:

(I say it in Amman, and whether my singing is accepted or not), we observe that the repetition of the subject active participle such as (Shafi', Raei', Nafi', Nazi', Sati', Yafi', Taei', Wasi', Lami', and Dafi') ${ }^{10}$, as the poet's repetition made an internally beautiful rhythm. This stems from the poet's commitment to the necessities of rhyme, so, these words came as rhymes of the mentioned verses in the poem, and then this repetition came to help and strengthen the rhythm of the idea, he repeats this feature to recognize its significance in the mind of the recipient; it is one of the factors that move and strengthen significance where most of these repeated words within this formula came closely related to the poet and his conditions, and this repetition unveils the poet 's status. The repetition of morphological formulas makes, alongside connecting lines to each other, a musically equal rhythm in spite of the characters mismatch" (Rbayah, 1995, p.20 ). The poet's selection to repeat the formula (subject active participle) in his poem was successful, because the formula of subject name has many unique features which are characterized among other morphological formulas as the subject active participle has double semantic mutual nature" (Hindawi, 2008, p.232).

Al-Ahwas said:

My gaze revealed a great deal of my infatuation

And more is the infatuation I hide in my heart

And how longing for someone forces tears

For whom who left home willingly? ${ }^{11}$

The subject active participle indicates static significance from a standpoint, as opposed to the verb indicating the regeneration in reality, if we look at the subject active participle repeated in the poem in terms of being a noun which is distinct from the verb in these positions, it indicates stability and inertness.

Dissimilar linguistic roots in the poem reveal, undoubtedly, a rhythmically apparent role, and a significant comparison between the formulas mentioned. Here, the poet attempts to show the contrast or similarity between those vocabularies where musicality included them all inside a tone stemming from rhyme and rhythm.

Here are some examples on this kind of rhythm by the poet as follows:

I swear to reach you the more you do

And all that I'll praise to no matter who. ${ }^{12}$

Or saying:

Release a captive whom you captivated too long

In fetters still when all captives are released. ${ }^{13}$

Or saying:

In love I wish the beloved be

And all absorbed in all they see

\footnotetext{
${ }^{8}$ Al-Ahwas's poetry, (P. S), p 206.

${ }^{10}$ Al-Ahwas's poetry, (P. S), p145.

${ }^{11}$ Al-Ahwas's poetry, (P. S), p 147.

${ }^{12}$ Al-Ahwas's poetry, p 78.

${ }^{13}$ Ibid (P. S), p 89.
}

9. see Tabrizi, K, Diwan Abi Tammam, Dar Alma'refah, Part 1, p. 56 and Al-Hamdani, I. (2013).The structure of the parallelism in the poem the conquest of Amuriyah, Journal of the College of Basic Education, Babylon University, 13, 66-74. 
A face decorated with pearly lips

Well described by story tellers

To your lands your grandfather called me

To strengthen relations and generous he be

To build on his ancestors' glory

And show the way coming generations. ${ }^{14}$

or saying:

I suffered a huge debt that you bore for me,

And what a debt bearer you are!

Your generosity I'll thank

So wonderful to echo everywhere.

Praising you with my best poetry

To others I would never do.

When poetically of you I speak

The best only for you I take. ${ }^{\mathbf{1 5}}$

or as saying:

For my neighbor I deeply carry and truly have

All the feelings neighbors deserve. ${ }^{16}$

or saying:

To my reproach his ears he seals

While silly things he willingly hears. ${ }^{17}$

Or as saying:

To morals my people were born

As such born when people torn

And morals they wholeheartedly bear

When other these morals fear

Early people refused morals. ${ }^{18}$

or saying:

I saw so many bad things

Bad seer for that I am called. ${ }^{19}$

or saying:

I longed more for love when forbidden

For it is in man's nature to do when forbidden. ${ }^{20}$

or saying:

So mush bending when walking

That viewers are always riddled. ${ }^{21}$

or saying:

Such a strong medicine to treat that

But commode softened and never his heart. ${ }^{22}$

or saying:

To your promise I sleep and wake

For you a promise never brake. ${ }^{23}$

\footnotetext{
${ }^{14}$, Ibid (P. S) p 96.

${ }^{15}$ Al-Ahwas's poetr (P. S), p 171.

2 Ibid (P. S) p 133.

${ }^{17}$ Ibid (P. S), p 139

${ }^{18}$, Ibid (P. S) p143.

${ }^{19}$ Ibid (P. S), p 151.

${ }^{20}$ Ibid (P. S), p 153.

21 Ibid (P. S)d, p 162.

${ }^{22}$ Ibid (P. S),, p167
} 
In those verses, we noticed the combination between derivatives, past or present tense verbs and infinitives, multiple present tenses, the singular and plural and many more. ${ }^{24}$

Al-Ahwas didn't only revolve around the similarity of morphological formulas to achieve rhythm, but he also covered parallelism which is fully done by repetition. The repetition of formulae makes a rhythm, and the rhythm confirms the idea. Such parallelism can occur either by making it into one verse or line, or a group of lines controlled by a single idea, but with different contexts. The second pattern of repetition in terms of rhythm and structure is the repetition of one linguistic pattern in the first hemistich, and this pattern elaborates as in the precedent one in Al-Ahwas's poetry, saying:

Praise the generous, they are always remembered

Givers when no one is to be asked..$^{25}$

Forbidders whose word is never broken,

Promisers who keep their promises.

Sayers who are well heard,

And keepers of trust. ${ }^{26}$

The dominant linguistic layout in the first half consists of the (If clause). The poet was repeating a linguistically specific pattern that the recipient would understand and expect to be repeated, but the poet wouldn't repeat it. Instead, he repeats another pattern or another formula after several verses, even if these patterns become expected; he goes a little bit and then stops again, and so on. Thus, the poem seems to be based on an almost exact approach of succession swinging between establishing a certain system and breaking it and then making another one and breaking it again. This approach is a basic feature in the poetic text in general, and there is no doubt that changing the rules of the constructive formats is the most powerful way to reduce the amount of void in the creative text (Romiah, 2006); once the reader adapts himself to anticipate certain patterns and puts himself a system to predict what he has not read yet, the structural base changes defying all his expectations. Hence, all voids and words get values in the light of the changing structure. The most common kind of repetition; the repetition of one linguistic pattern increases, as we have seen and words appear respectively according to one grammatical style committing to the same morphological formulas to represent this type of repetition.

Such as saying:

Faith and wealth remain in people as long as they live

And these are lost when those are lost.

No matter how hard I may try to make my poetry count their glory

I will not be able to mention more than a tenth of their glory. ${ }^{27}$

Repetition creates a stream of expectation, and gives unity to the work of art since parallelism in these sequences of lines, that I viewed, was apparent and straightforward. So, if we parted sequences depending on grammar, we will find that parallelism, for example, came in other examples in the form of a present verb, apparent subject or its substitute, and then he decided to use this kind of repetition to produce parallel musical units based on linking verses to one another using a musical toning based on balance and parallelism.

This repetition reveals expressive possibilities and artistic energies that enrich the meaning and make it authentic. The poet was able to control it, and put it in its right place, so as to achieve an artistic fixed service at textual level depending mainly on repeating what the poet wants to confirm or disclose away from using stylistic stereotype. Thus, the text become coherent, strong, and free from vulnerability and weakness.

(3)

Epanalepsis: Rhetoricians define it as a repetitive structure based on inserting a word at the beginning of speech, then repeating this word in the end "any verse or prose speech whose beginning matches its ending in one of the shapes" or "a speech whose beginning signifies the end of it as well as the correlation between both" (Nseer, 2005, p. 49) One of the forms of this repetition is to have one of the two words at the beginning of the first hemistich and the second one in the end of the second hemistich.

As Al-Ahwas said:

Moving wishing to see Om Jaafar

In your house or I move not,

I visit the houses close to hers

And my heart longs to the house that I cannot visit. ${ }^{28}$

${ }^{23}$ Ibid (P. S), p103.

${ }^{24}$, Ibid (P. S )p 106

${ }^{25}$ See from the examples of Al-Ahwas's poetry (P.S), pp. 78, 80, 88, 89, 93, 96, 97, 103, 119, 122, 125, 128, 133, 150, 162, 163.

${ }^{26}$ Al-Ahwas's poetry, (P. S), p 96.

27 Al-Ahwas's poetry, (P. S), p 98

${ }^{28}$ Al-Ahwas's poetry, (P. S), p 98. 


\section{And saying:}

They said I went thin and I was tough

And the least is getting thin.

And if whining returns something back

I would whine if whining works.

And if returning makes people happy,

I will not ever be happy with returning.

It sounds as if you have never met a fellow,

When lonely leaves you that fellow.

Patience on events along your path,

The mortality ends every being's path. ${ }^{29}$

Sometimes, the last word in a poetry line is almost like and the last word in the first half. This is a kind of rhythmic means, which represents a closed-loop where the first speech is associated with its end (Quinn, 1990; Fadl, 1992).

As the poet said:

And in a special dwelling in my heart, you dwelled

Where, I swear, nobody has ever dwelled ${ }^{30}$

This type could be similar in value of repetition to Epanalepsis or contribution where the first hemistich includes a word that is the same as the last of the second hemistich, in case rhyme was known, before the second hemistich itself. Contribution is identified as the enrichment which makes the meaning of the line included in, proved by, referred to, and resulting in the rhythm. As saying:

A 'Aslam, you captivated me, so release me

The generous releases the captives.

I advise you and I know

Cheaters are the same to you as givers of advice ${ }^{31}$

And saying:

I swear I had never entrusted my secret and hers to others

For fear they would expose our secret. ${ }^{32}$

And saying:

Oh you who blames me to leave her

You exaggerated if an exaggeration was enough. ${ }^{33}$

And saying:

Oh Atekah's house which I never reached

Avoiding enemies while the heart is stuck to you.

I would grant you the abandonment but

I swear I am fond of you with abandonment ${ }^{34}$

Perhaps the first repetitive structures formed at a horizontal level in Al-Ahwas's poetry are Epanalepses; because it is common and that makes it a rich material for study. The one who looks deeply in this repetitive structure can notice that it depends on the conversion of expressive forms to a closed structure, whose beginning comes closely with its end. Repetition in (release/releases, accept/accet, etc.) causes us to say that the rhythmic symmetry generated by the repetitive words identical in construction was transformed, through contextual linking vocabularies to one another, to a correspondence between the parties of the repetitive structure.

In the poet's lines of poetry "narration that they narrated" and "glory that they glorified", etc., are voices that broadcast rhythmic vocal symmetry and transform this symmetry to a movement of continuity through related linguistic vocabularies in poetic context. Rhythmic symmetry may have contributed to the movement which had an opposite meaning when attribution was negated, as in "does / does not do".

Epanalepsis: is one of the forms of rhythmic repetition prospered in Al-Ahwas's poetry. The poet repeated it in different forms, and each repetition was carrying an implication different from the previous one, by adding a new effecting

\footnotetext{
29 Al-Ahwas's poetry (P. S), p173.

${ }^{30}$, Al-Ahwas's poetry (P. S), p 166.

${ }^{31}$, Al-Ahwas's poetry, (P. S),, p 89.

${ }^{32}$, Ibid (P. S), p 119.

${ }^{33}, \operatorname{Ibid}($ P. S) p 122.

${ }^{34}$ Ibid, (P. S) p 167.
} 
enjoyment. This repetition represents a circular motion which has uniqueness and excellence extended context. So, repeating a word in the end of each poetic stanza causes a fully emotional wave of flow which breaks the barrier of monotony and isolation, and leads to a consistent text and a harmonious text plot. Hence, the circular repetition of a word intensifies connotations and forms a sequential movement which enriches the structure of the poetic text at the semantic and verbal levels together.

The poet said:

My own eyes accept what she accepts

And the best thing is what the eye accepts. ${ }^{35}$

The rhythm in the Epanalepsis means having two repeated or same words; one is in the end of the line and the other one is before one of these five positions of the line, namely: the first hemistich, its filling, its end, the second hemistich, or its filling. Al-Qurawani (1988, p. 72) stated that Epanalepsis is similar to repetition, but the difference between them is that Epanalepsis is concerned with rhythms in the first hemistich, while repetition is located in the doubled line". Thus, Epanalepsis is a type of rhythmic melody repetition, and the structure of rhythmic Epanalepsis is generated by the main rhythmic structure with its two parts; rhyme and rhythm. It is also called "the similarity of parties", as a word tends to be repeated and carries a different context at each place. In the second hemistich, the poet insists on having new overtones and dimensions about something which lies in its first hemistich.

Al-Ahwas said:

And if pearls filled people's faces with beauty

Your face would beautify the pearls ${ }^{36}$

And said:

If people needed a lord

They would, if they could, make you their lord

He said:

I wish to find a way to Um Juhdar,

For patience for not seeing her makes me lose patience. ${ }^{37}$

He said:

You always tended to do me

Favors before which you did favors. ${ }^{38}$

He also said:

A visitor I am not but passion moves me around

If not visited I have to visit,

I visit and I don't stop visiting whenever

I see an enemy pointing at me.

And said:

If I dissuaded, I swear

You would stay my beloved more than whom I visit and enter ${ }^{39}$.

In the following example: the poet uses contrastive parallelism represented by (heat against coldness). The contradistinctive parallelism is the similarity between two consecutive parties which are antonyms but equal at the level of the compositional structure:

My heart needs to forget Asmaa'

And it consoles itself but there is no consolation ${ }^{40}$

Hot in a winter and cold in a summer; a bright lantern in a dark night ${ }^{41}$

Also saying as praising:

The wealthy are contented with their deeds

And the generous are modest in their eyes. ${ }^{42}$

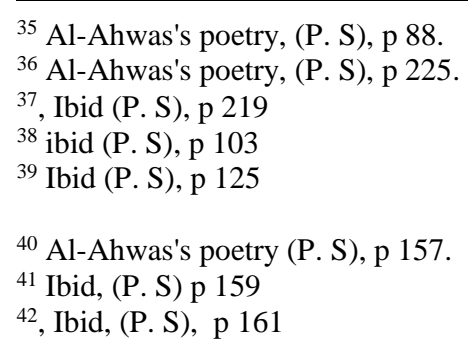


Death occurs at times

And it boards rain that revives people. ${ }^{43}$

Or saying

Every beloved has forgotten me or died

And I have never forgotten or yet died. ${ }^{\mathbf{4 4}}$

It should be noted that these two structures have achieved two types of parallelism, the first is based on the grammatical symmetry, and the second is based on the morphological similarity and semantic concordance.

Many people blame me for you when I sit with them

But I don't care whether blame spreads or not

I don't care if you stay my female neighbor,

Whether people stay or leave. ${ }^{45}$

Or saying

I hope she is near even if she is far

And things are hoped near they are far.

As his saying:

Oh Leilas' husband, how is her peace and my war

And between us there was a war for her.

She has the same guilt I have today if I was guilty

And I have not guilty if she has no guilt. ${ }^{46}$

These structural parallelisms based on concordance are understood by the use of contradictions raised by such parallelism. Thus, a movement of rhythm related to the text appears amidst contradictions and breakdowns. These parallelisms have achieved a series of acoustic constructions based on similarities and symmetry between each two sentences structurally and grammatically.

We note in the following lines parallelism between words; and we also find parallelism at the level of characters, words, and phrases. In the third example, we can also observe that the compositional level is subject to an equivalent and accurate parallelism since the first hemistich consists of (stressing letter + relative pronoun + verb + adjective + name, and the same thing is found in the second hemistich of the same example, and this is known as the fully structural parallelism. The second hemistich may begin with a letter that does not exist in the first hemistich, and this is called "the first partial structural parallelism".

Another example of the morphological parallelism is apparent in Abi Tammam's poem on the conquest of Amuriyah when the poet repeats the same word (Conquest) twice; once as a name and once as a verb ${ }^{47}$. This occurrence plays a great importance of linking the compositional and the semantic structure in verbal event. This contributes to the elaboration of a parallel format adopted a sequence which is called morphological rhythm.

The results of the study corresponds Aziz's definition of parallelism as putting comparable ideas into parallel structures makes it easier to track the writer's train of thoughts. This results in having the text that is structured by placing words of the same part of speech and phrases and clauses in parallel way. They are also in line with Fabb's (1997) definition of parallelism as a sameness amongst two sections of a text structurally or semantically where two sections of a text are from the same level of structure (e.g. phrase structure) and can be interpreted as having the same meanings.

The previous analysis of parallelistic features is in agreement with Al-Subhi's (2009) analysis of parallelism as a stylistic device and a foregrounded regularities activated in Eloise Greenfield's poetry on different linguistic levels simultaneously: phonological, grammatical, and semantic. On the phonological level, she found sound parallelism played a dominant role over other types of parallelism which are rhyme (e.g. masculine and full rhymes), alliteration, assonance of diphthongs, and consonant parallels. She also found that both grammatical parallelism and sound parallelism accomplished a similar statue in Greenfield's poems. Morphologically speaking, she found parallel adjectives, adverbs, and pronouns were less used compared to parallel nouns and verbs. On the syntactic level, the most frequent used type was parallel noun phrases. The least existing type is lexical/semantic parallelism. The simple parallel constructions, anaphoric parallelism and hyponymous parallels were the dominant pattern.

The study is line with Aziz (2012) claim that parallelism is a stylistic means of repetition and cohesion; it is a technique where words are organized in consecutive lines in a well-adjusted manner examining the types of parallelism in Arabic and religious prayers. In contrast with the present study, Yosef (2007) who detected parallelism and repetition in Dakhel

\footnotetext{
${ }^{43}$, Ibid (P. S), p 98.

${ }^{44}$ Ibid, (P. S) p 99.

${ }^{45}$, Ibid (P. S), p 101.

${ }^{46} \mathrm{Al}$-Ahwas's poetry (P.S), p 101

47. see Tabrizi, K, Diwan Abi Tammam, Dar Alma'refah, Part 1, p. 71 and Al-Hamdani, I. (2013).The structure of the parallelism in the poem the conquest of Amuriyah, Journal of the College of Basic Education, Babylon University, 13, 66-74.
} 
Al-Khalifah's poetry clarified the difference between parallelism and repetition and stated that both are prominent stylistic devices that characterized poetry.

As a comparable example of other poet's employment of parallelism is the one illustrated in Khader and Kullabs' (2016) study. The researchers examined the manifestations of parallelism in Sa'adi Yusuf's poetry to get the knowledge of its structural forms, its connotative powers and its expressive ability, that offer the generous opportunity to innumerable readings, preparing the reader to be accustomed to the experiences of the inspired person, his/her artistic revelations, and his/her resourceful potentialities. The present researchers mention some other examples of parallelism cited in Khader and Kullabs' (2016) study. The researchers illustrated an example of morphological parallelism as follows:

\section{Drinks the lark \\ Drinks the star}

Drinks the sea, the birds, and the home plants drink

\section{But the kids "of sabra"}

Drink the bombs smoke ${ }^{48}$

The repetition of the word "drink" in all the poetic lines installs the denotation in mind and consciousness of the reader about the regularity of the action in life, whereas the usage of the word in the last line dismantles that regularity and shocks the readers with nature of the regular drink of Sabra children (i.e. from clean water to the smoke of the bombs). It also grants the text the rhythm of the sounds energies that enriches its denotative side.

As an example of synonymous parallelism that indicates the entity of the meaning in the mind of the poet in Yousf's poetry is in the following poetic lines:

The winter rolling his coat above the snow

The winds were crazy

The cold violent winds shakings, as if by cold injured ${ }^{49}$

These lines demonstrate the artistic picture that the poet has painted in this scene. The ingredients of this picture (i.e. winter - coat - snow - the crazy cold-violent winds-shaking because of the severe injury) were taken from the environment to broaden the denotative profound meanings of the picture and to attain the lexical parallelism amongst its language units which in turn helps the poetic meaning of the poetry lit.

An example of syntactic parallelism employed in Yousf's poetry is evident in the following poetic lines:

A candle in the long road

A candle in the sleep of the houses

A candle for the canteens, terrifying, a candle for the beakers

A candle for the journalist shaking in an empty office

A candle for the injured, a candle for the frank speech ${ }^{50}$.

The repetition of the format of the nominative sentence (aljomlaalismiya) serves a dramatic paradox which denotes subjugation and deep darkness in contrast to the other denotations of life optimism, and light.

\subsection{Types of Structural Parallelism}

There are two types of structural parallelism:

1. Full structural parallelism: when elements of the line are equal in their compositional structures and consistent with the grammatical and customary functions they perform.

2. Partial structural parallelism: when the elements and the sequences of the parallel sides have identical grammatical structures and different compositional structures because of addition, omission, or inference.

Structural parallelism here achieves a relative accumulation through a strong construction based on interdependence, logical relations as well as compositional and semantic succession (the successive conjunctions that link parts together, and link images to one another in order to form this artistic coherent structure). Structural parallelism has been achieved as a result of this as follows:

Negation tool + starting noun + prepositional phrase + prepositional nominal phrase + predicate .

As he said:

The soul is never resting because of its distress

And it is not with what life brings resting

I neither attributed people, nor did I enjoy rest.

\footnotetext{
48. Yusuf, Sa'adi, (1988). Diwan Sa'adi Yusuf [Poems of Sa'adi Yusuf], 2, p273.

49. Yusuf, Sa'adi, (1988). Diwan Sa'adi Yusuf [Poems of Sa'adi Yusuf], 1, p493.

50. Yusuf, Sa'adi, (1988). Diwan Sa'adi Yusuf [Poems of Sa'adi Yusuf], 2, p255-256.
} 
And I visit the house that I love

And I abandon the house although it is my most beloved.

I if I come happily

Unhappily your face looks at me. ${ }^{51}$

Or in his saying: conjunction + present tense + prepositional phrase:

And I overlook a lot I don't like about you.

And when invited to what pleases you, I answer. ${ }^{\mathbf{5 2}}$

And said:

And I deprive myself from you although it wishes you near

And the way to you is near. ${ }^{53}$

Or saying:

By God, I swear to reach you the more you do

And all that I'll praise to no matter who.

And I take what you kindly give

And I distance and hate what you hate

He also shows partial structural parallelism in saying:

I cried my youth not caring for blamed

A friend would cry along and make me happy.

Or saying:

I hope she is near even if she is far

And things are hoped near they are far.

He would not realize it when she is near

And when far, he is torn by her love. ${ }^{54}$

The parallelism of synonymy is the similarity between two consecutive elements to prove the same semantic meaning. Such parallelism can be in an expressive different form and consistent content as in his saying: likening his well proven love:

Her love has been nailed in the chest

As fingers have been nailed in palms. ${ }^{55}$

From the above discussion, it is apparent that Al-Ahwas achieved a high rhythmical harmony using parallelism, where the parallel terms formed musical accessories and basic tones that fell into interesting acoustic harmonious atmosphere based on qualitative and quantitative compatibility of sounds. They also achieved a semantic goal by making this creative technique basically and closely related to the meaning where he deliberately tended to intensify parallel words and functioning units in a network revolving around the dominant idea.

This parallelism is a form of text cohesion and interdependence of its parts, and it is deemed an effective element in strengthening the text plot, linking the text at a high level of organization and balance, thus, it is a total image that rounds the text and surrounds it, but it is made up of multiple parts, for parallelism reveals unexpected renewable potentials in responsive hymns of music which is a distinctive rhythmic phenomenon.

This stylistic analysis of parallelism comes in Al-Ahwas s' poetry as an attempt to detect the stylistic and aesthetic dimensions of this technique. In his poetry, we find a series of parallels full of similar sound rhythms and demonstrate semantic juxtaposition. Comparison means .comparing the utterance with its order in speech, originally, ordering the speech depending on the way it should be. So, the initial utterance comes first, and the final utterance comes last, and the corresponding utterance comes along to what it corresponds, and the differing comes along with what it differs. The contrast or juxtaposition is not a luxury style but, when it appears in the right position, it is spontaneous, and if the meaning needs it, it makes the speech influential, persuasive and more beautiful. Shartah (2005) examined some stylistic features of Badwi Al-Jabal's poetry and among them are: deviation and parallelism. Patterns and functions of parallelism and deviation were illustrated.

This regularity in components is purely harmonious and compatible, and it is really a splendor aesthetic form in his poetry. It is also obvious in this poetry that parallelism, based on semantic and metaphoric juxtaposition is one of the

\footnotetext{
${ }^{51}$ Al-Ahwas's poetry, (P. S), p 102.

${ }^{52}$ Ibid, (P. S), p 103.

${ }^{53}$ Al-Ahwas's poetry, (P. S), p 103.

${ }^{54}$, Ibid, (P. S) p 103.

${ }^{55} \mathrm{Al}$-Ahwas's poetry, (P. S, p 102
} 
main stylistic techniques has the ability to produce an aesthetic text on one hand, and demonstrates significance on the other hand. It plays effective roles in drawing the recipient's attention, which really has an excellent rhythmic musicality, as well as myriad facets of rhythmic alliteration, repetition, and vocal synonymy. These repetitions contributed to the creation of musical tones resulting from the interaction between sounds and meanings in the text.

It is evident that the results of this study lends support to Parry's (2007) findings in that presenting a panoply of parallelisms in the poetry can fulfill certain functions. It gives a general sense of contentment to the reader, proving that the text is more comprehensible, more beautiful, and more expressive. It also helps draw readers' attention to details in the text which enhances the possibility that elucidations will be verifiable in the text itself and not just in the eye of the readers. Besides, parallelistic analyses display the orderliness and complexity of the text, proving that the text is not chaotic or devoid of form. Parallelistic features could further help readers divide the text into its originally intended segments or units, and link counterparts in the text properly to each other, thus they give evidence of the stylistic preferences of individual authors. The findings are also in line with Al-Subhi's (2009) who asserted that these patterns of parallelism create unexpected effects upon readers to varying techniques showing the regularities of sounds, words, and structures that characterize the style of poets. The findings also confirm Al-Zebadi's (2007) finding that parallelism is one of the most vital devices of poetic language that plays a crucial role in conveying the poet's message. They are consistent with Al-Saamady's (2001) and Khourany's (2007) outcomes that parallelism enriches the denotation, deepens the meaning, increases the connotative space of the text, the denotative and aesthetic energies and the textual effects. The study also ratifies Aziz (2012)'s conclusion that parallelism can be used as syntactic and semantic interconnection and unity device that binds the elements of a text together to create a complete meaning and support the power of persuasion.

\section{Conclusion}

The study is a meticulous examination of Al-Ahwas's poetry. It presents a full array of all kinds of parallelistic structures evident in Al-Ahwas's poetry. The poet "Al-Ahwas Al-Ansari" achieved a rhythmical harmony using parallelism. A tone is nothing but music engineering that qualifies the phrase and enriches the meaning. Parallel terms formed musical accessories and basic tones which created an interesting acoustic harmonious atmosphere based on qualitative and quantitative compatibility for sounds. They also achieved a semantic goal by making this creative technique basically and closely related to the meaning where he deliberately intends to intensify parallel words and functioning units in a network revolving around the dominant idea. Parallelism also puts in our hands the key to the poet's dominant idea, and so it is an unconscious spotlight on the poet's depths that he enlightens for people. It is also a part of the emotional cleverness for a sentence in which the poet tries to organize words, so that he can build an emotional base of a certain kind. Finally, it is hoped that this study paves the way for future avenues of studies in the world of different types of literature under the category of stylistics.

\section{References}

Al-Assad, K. (1999). Repeating forming in madaneah sewar: Stylistic Phenomenon, Unpublished MA thesis, Jordan, Yarmouk University.

Al-Gharaibeh, A. (1999). Repeating rhythm in King Abdullah Bin Al Hussein s' poetry. The Jordanian Journal of Arabic Language and its Literature, 4(3), 143-165

Al-Maqalah, A. (1981). Al-Shear bain al-ruaia w al-tashkeel, Beirut, Al-Awadah Dar.

AL-Qura'an, F. (1996). Al-takween al-tekrari in Jameel Muamar s' poetry. Muta for Researches, 6 (1) 94-110

Al-Qura'an, F. (1999). Rhetorical parallel techniques "Representatives" of Nizar Qabbani. Arab Universities Union Magazine, 6(1), 65-78.

Al-Samarrai, I. (1960). Al-Fael wal buniah, Morocco, Al-Resalh Company.

Al-Shirazi, M. (1896 ). Al-muheet dictionary, Beirut, Dar Al-Jeel.

Al-Subhi, A. (2009). Parallelism in selected children's poems by Eloise Greenfield: A stylistic study. Unpublished MA thesis. Kingdom of Saudi Arabia, Umm Al-Qura University.

Al-Wali, M. and Hanoon, M. (1988). Poetic issues, Roman Jacobson, translation. Morocco, Toubkal Publishing House. Agha, A. (2007). Semantic parallelism in illiteracy (Layla al-Akhyaliyya). Journal of Education and Science, 14(3), 151-168.

Aziz, R. (2012). Parallelism as a cohesive device in English and Arabic prayers: Contrastive analysis. Al-Ostath, 201, 353-371.

Al-Qurawani, I (1988). Al-omdah fe mahasen al-she'ar. Beirut, Dar Aljeel.

Al-Zbaidi, A. (2007). Layers of grammarians and linguistics. Jordan, Dar Al-Maarf.

Bin Zakaria, A. (1972). Glossary standards language. Damascus, Dar Al-Fikr.

Bouraoui, M. (2006). Eloquence redundancy in lamentations of Khansa, Journal of Humanities, 9, 1-12.

David, I. (2006). Parallelism technique in modern poetry, Literary Trend Magazine, 1(2).

Fabb, N. (1997). Linguistics and Literature in the Verbal Arts of the World. Oxford, Blackwell Publishers.

Fadl, S. (1992). Stylistic science and discipline and procedures. Cairo, Al Mukhtar. 
Guillén, C. (1987). On the uses of monistic theories: Parallelism in poetry. New Literary History, 18(3), 497-516. DOI: http://dx.doi.org/10.2307/469055.

Habil, A. (2014). Parallelism phenomenon in the poetry of Imam Shafi'i, The Open Al-Quds University Journal for Research and Studies, XXXIII, 103-136.

Hindawi, A. (2008). Morphological amenability in Holy Qur'an, applied theoretical study, Jordan, The Modern World of Books.

Jacobson, R. (1988). Poetic Issues, translation: Mohammed AL Wali and Mubarak Hanoon, Toubkal Publishing House, Casablanca - Morocco.

Jama, A. (1970). Al-Ahwas Al-Ansari's Diwan, Cairo, Al-Khanji Library.

Khader, K. and Kullb, M. (2016). The structure of parallelism in Sa'adi Yusuf's Poetry. International Journal on Studies in English Language and Literature, 4(2), 39-51.

Khatib, I. (1982). Theory of formal curriculum, texts of Russian formalists, translation. Beirut, The Moroccan Company for United Publishers, and Foundation of Arabic Researches.

Knoni, M. (1999). Parallelism and language of poetry. Thought and Criticism Magazine, 79(18), 3-14.

Matloob, A. (1987). Glossary of rhetorical and development, Iraq, Publications of the Iraqi Scientific Complex.

Muftah, M. (1999). Poetic Discourse Analysis (A Strategy of Intertextuality). Morocco, Arab Cultural Center.

Muftah, M (1996). Similarities and differences, about a holistic methodology. Morocco, the Arab Cultural Center.

Muftah, M. (1997). Introduction to reading the poetic text. Fusool Magazine, 16(1). 12-22

Nseer, A. (2005). Repetition in Al-Akhtal poetry. Muta for Researches, 8(20), 28-52

Parry, D. (2007). Poetic parallelisms in the book of Mormon: The complete text reformatted. United States of America, The Neal A. Maxwell Institute for Religious Scholarship.

Quinn, J. (1990). Building language of poetry, translation by Ahmed Darwish, Cairo, General Authority for Cultural Palaces.

Qtous, B. (1999). Rhythmic Structures in Mahmoud Darwish s' Group (Hesar Lmeda'ah AL Baher), Journal of Yarmouk Research, 9(1).63-72

Quinn J. (1990). Building language of poetry, translation by Ahmed Darwish, Cairo, General Authority for Cultural Palaces.

Rawashdeh, S. (1998). Parallelism in the poetry of Joseph Sayegh and its impact on the rhythm and meaning. Journal of Yarmouk Research, 16 (24) 9-18.

Rbayah, M. (1995). Repetition in Pre-Islamic Poetry, a stylistic study. A paper presented in the second literary critisim conference, 4-22, Irbid, Yarmouk University

Romiah, W. (2006). The poetry and the critic from structure to vision. Kuwait, The Series of the Knowledge World for the National Council for Culture and Arts.

Salah F. (1992). Stylistic Science and discipline and procedures. Cairo, Al Mukhtar Corporation.

Saliba, J. (1982). Philosophical Arabic of Arab, French, English and Latin lexicons. Lebanon, Lebanese Book Dar.

Shartah, E. (2005). The aesthetics of repetition in Al-Suri's poetry, Damascus, Dar Rand for publication and distribution.

Short, M. (1996) Exploring the language of poems, plays and prose. London: Longman.

Sultan, G. (2011). Parallelism in a poem by Mahmoud Darwish (lover of Palestine). College of Basic Education Research Journal, 11(2) 361- 377.

Thamer, F. (1987). Critical orbits, in the problem of criticism, modernity and creativity, Iraq, the Ministry of Culture and Information, House of Cultural Affairs.

Waugh, L. (1980). The Poetic function in the theory of Roman Jakobson. Poetics Today, 2(1a), 57-82. http://dx.doi.org/10.2307/1772352.

Yusuf, S. (1988). Diwan Sa'adi Yusuf [Poems of Sa'adi Yusuf] Beirut. Dar Alawda. 